\title{
Antibacterial to antifungal conversion of neamine aminoglycosides through alkyl modification. Strategy for reviving old drugs into agrofungicides
}

\author{
Cheng-Wei T Chang ${ }^{1}$, Marina Fosso ${ }^{1}$, Yukie Kawasaki ${ }^{2}$, Sanjib Shrestha ${ }^{2}$, Mekki F Bensaci ${ }^{2}$, Jinhua Wang ${ }^{1}$, \\ Conrad K Evans ${ }^{2}$ and Jon Y Takemoto ${ }^{2}$
}

Many Actinomycetes aminoglycosides are widely used antibiotics. Although mainly antibacterials, a few known aminoglycosides also inhibit yeasts, protozoans and important crop pathogenic fungal oomycetes. Here we show that attachment of a C8 alkyl chain to ring III of a neamine-based aminoglycoside specifically at the 4 "-o position yields a broad-spectrum fungicide (FG08) without the antibacterial properties typical for aminoglycosides. Leaf infection assays and greenhouse studies show that FG08 is capable of suppressing wheat fungal infections by Fusarium graminearum — the causative agent of Fusarium head blight-at concentrations that are minimally phytotoxic. Unlike typical aminoglycoside action of ribosomal protein translation miscoding, FG08's antifungal action involves perturbation of the plasma membrane. This antibacterial to antifungal transformation could pave the way for the development of a new class of aminoglycoside-based fungicides suitable for use in crop disease applications. In addition, this strategy is an example of reviving a clinically obsolete drug by simple chemical modification to yield a new application.

The Journal of Antibiotics (2010) 63, 667-672; doi:10.1038/ja.2010.110; published online 6 October 2010

Keywords: FG08; fungicide; Fusarium head blight; kanamycinB

\section{INTRODUCTION}

Among the oldest and most widely used antibiotics are certain aminoglycosides produced by Actinomycetes. They include the classical aminoglycosides streptomycin, neomycin and kanamycin and newer versions amikacin, gentamicin and tobramycin. They act by binding to the aminoacyl-transfer RNA decoding A site in ribosomal 16S ribosomal RNA to decrease the fidelity of protein translation. Although generally known as antibacterials, certain classical aminoglycosides are reported to inhibit important crop pathogenic fungal oomycetes, ${ }^{1}$ and structurally unusual ones inhibit yeasts and protozoans. ${ }^{2,3}$ The application of aminoglycosides to combat crop diseases, however, is controversial as the impact it may have on broader antibiotic resistance is debated and uncertain. ${ }^{4,5}$ The antibiotic aminoglycosides are generally viewed to act against bacteria. ${ }^{6}$ However, unusual bicyclic ring-containing aminoglycosides are additionally active against yeasts. ${ }^{7-9}$ A recent report revealed inhibition of plant pathogenic oomycetes Phytophora and Pythium sp. by neomycin, paramomycin, ribostamycin and streptomycin, although they showed comparatively little activity against several other fungal genera. ${ }^{1}$ Consequently, aminoglycosides are more accurately antibacterial or antibacterial and antifungal depending on the nature of chemical tailoring of the constituent amino sugars. Here, we demonstrate the third possibility of antifungal but not antibacterial capabilities.
Many crop, horticultural and turf diseases are due to fungal and oomycetes mold infections which globally cause enormous economic losses. ${ }^{10}$ Direct application of fungicides remains the prevalent strategy to control these diseases. ${ }^{10}$ However, concerns with inconsistent and declining effectiveness due to resistance, environmental impacts, animal and human toxicity and costs continue to challenge their use. Heavy use of triazole agrofungicides are linked to recent rises in human cases of invasive aspergillosis resistant to antifungal azoles. ${ }^{11}$ An example of the limitations of current agrofungicide use is illustrated by Fusarium head blight (FHB) — a destructive and costly disease of wheat, barley and other small grains caused by F. graminearum. ${ }^{12}$ There is a serious and persistent need for new agrofungicides that are efficacious, less toxic, cost effective and that do not promote resistance. Although potentially useful as agrofungicides, ${ }^{1}$ the application of currently available aminoglycosides to combat crop diseases is discouraged as such practices are predicted to promote bacterial resistance to therapeutically used antibiotics. ${ }^{5}$

Kanamycins A, B and C produced by the soil microbe Streptomyces kanamyceticus are among the most successful antibacterial aminoglycosides. ${ }^{13,14}$ They are structurally based on sugar rings I and II composed of 4-o-(6-amino-6-deoxy- $\alpha$-D-glucopyranosyl)-2-deoxystreptamine, neamine and paromamine, respectively, with an attached ring III of o-6-linked kanosamine. Ototoxic and nephrotoxic at high

${ }^{1}$ Department of Chemistry and Biochemistry, Utah State University, Logan, UT, USA and ${ }^{2}$ Department of Biology, Utah State University, Logan, UT, USA Correspondence: Dr JY Takemoto, Department of Biology, 5305 University Hill, Utah State University, Logan, UT 84322, USA. E-mail: jon.takemoto@usu.edu

Received 25 July 2010; revised 8 September 2010; accepted 9 September 2010; published online 6 October 2010 
doses, the original natural product kanamycins are now mostly obsolete and confined to treating mycobacterial infections. They have been largely replaced by semi-synthetic analogs (for example, amikacin, dibekacin and arbekacin) that are chemically modified in the 2-4-o-(6-amino-6-deoxy- $\alpha$-D-glucopyranosyl)-2-deoxystreptamine and ring I aminosugar moieties and now broadly used clinically. ${ }^{15-18}$ Earlier attempts to improve antibiotic efficacy with modifications in the ring III moiety were limited to chemical variations at the $\mathrm{C6}$ " position. ${ }^{19,20}$

Recently, we developed protocols to stereoselectively attach $\alpha$ glycosyl donors to an 'optimized' disaccharide neamine core to produce novel kanamycin class aminoglycosides. ${ }^{21-23}$ With this capability, glycosyl donors with structural variations can be used to create a library of kanamycin analogs altered in ring III. Structure-bioactivity screens of libraries of these analogs uncovered a few compounds that inhibited the growth of fungi and yeasts. One compound, FG08, described here in detail, displayed broad spectrum fungicidal activity with concomitant loss of antibacterial activity and a novel mechanism of action for antimicrobial aminoglycosides.

\section{MATERIALS AND METHODS}

\section{Chemical syntheses}

Compound FG08 and its analogs (Supplementary Figure 1) were synthesized through successive regio- and stereoselective glycosylation of an azido neamine core, deacetylation, Staudinger reduction of azido groups and hydrogenolysis of benzyl groups using previously described methods ${ }^{21}$ (Figure 1). Analogs JL022, JL029 and JL033 and the alkylated glycosyl donor (phenyl 2,3-di-o-benzyl-6deoxy-4-o- $n$-octyl-1-thio- $\beta$-D-glucopyranoside) for FG08 were synthesized as described previously. ${ }^{23}$ Details of the general synthetic procedures are presented in Supplementary Information.

\section{Organisms and culture conditions}

Fusarium graminearum strains B-4-5A and Butte86 (ADA-11) were obtained from the Small Grain Pathology Program, University of Minnesota, Minneapolis. Escherichia coli ATCC25922, Staphylococcus aureus ATCC6538, Pseudomonas aeruginosa (ATCC 27853), Enterococcus faecalis (ATCC 29212), Klebsiella pneumoniae (ATCC 138883), Klebsiella pneumomiae (ATCC 700603), Rhodotorula pilimanae strains ATCC9449 and ATCC 26423 and Candida albicans ATCC10231 were obtained from the American Type Culture Collection (Manassas, VA, USA). Curvularia brachyspora was obtained from A De Lucca (Southern Regional Research Center, USDA, ARS, New Orleans, LA, USA) and E. coli strain B from the microbial culture collection of the Department of Biology, Utah State University, Logan, UT, USA. Rhizopus stolonifer, Fusarium oxysporum, Ulocladium spp., Pythium irregulare, Pythium ultimum, Phytophthora parasitica, Phoma spp., Bortrytis cinerea and Cladosporium cladosporioides were obtained from Dr B Kropp, Department of Biology, Utah State University. R. pilimanae Hedrick and Burke (ATCC 26423) was grown and maintained as previously described. ${ }^{24}$ S. cerevisiae W303 was grown on yeastextract peptone dextrose medium ${ }^{24}$ at $28^{\circ} \mathrm{C}$. All other fungi and oomyctes were cultivated in potato dextrose broth (Difco, BD, Franklin Lakes, NJ, USA) $+4 \mathrm{gl}^{-1}$ casamino acids (PDB-CA medium) ${ }^{24}$ at $28-30^{\circ} \mathrm{C}$. Bacterial strains were grown at $37^{\circ} \mathrm{C}$ for $24 \mathrm{~h}$ on Luria-Bertani medium ${ }^{25}$ except $S$. aureus ATCC6538 which was grown in Mueller-Hinton medium (Difco).

\section{In vitro antibacterial and antifungal tests}

Microbroth dilution assays for determination of minimal inhibitory concentrations (MICs) were conducted using the protocols of the Clinical and Laboratory Standards Institute. ${ }^{26,27}$ Bacteria were grown in Luria-Bertani broth medium and fungi were grown in PDB-CA medium. For disk diffusion growth inhibitory assays, cultures or conidia were spread on agar plate medium surfaces. Paper disks $(0.5 \mathrm{~cm}$ diameter $)$ were placed on the surfaces, and $8 \mu \mathrm{l}$ aliquots of test solutions were applied to the disks. Clear zones of inhibition were observed after incubation at $37^{\circ} \mathrm{C}$ (bacteria) or $28^{\circ} \mathrm{C}$ (fungi).
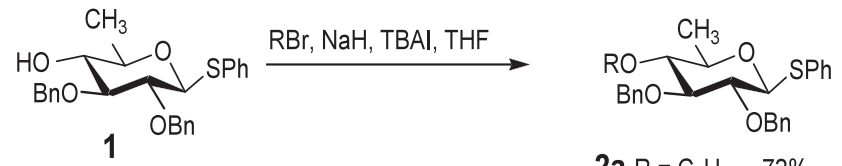

2a R $=\mathrm{C}_{4} \mathrm{H}_{9} \quad 72 \%$

2b R $=\mathrm{C}_{8} \mathrm{H}_{17} \quad 53 \%$

2C R $=\mathrm{C}_{12} \mathrm{H}_{25} \quad 64 \%$

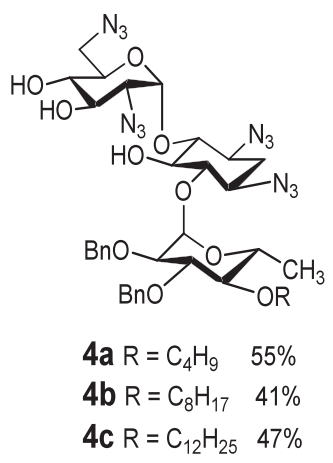

(i) $\mathrm{PMe}_{3}, \mathrm{THF}, \mathrm{NaOH}$

(ii) $\mathrm{H}_{2}, \mathrm{Pd}(\mathrm{OH})_{2} / \mathrm{C}, \mathrm{HOAc} / \mathrm{H}_{2} \mathrm{O}(1 / 3)$,

(iii) Dowex $1 \times 8-200$ (Cl-form). (a) $\mathrm{NIS}, \mathrm{TfOH}, \mathrm{Et}_{2} \mathrm{O}: \mathrm{CH}_{2} \mathrm{Cl}_{2}$ (3:1),

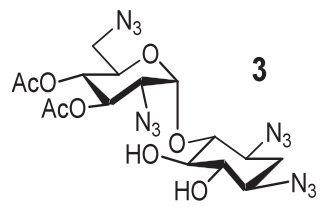

(b) $\mathrm{NaOMe}, \mathrm{MeOH}: \mathrm{THF}$ (5:1)

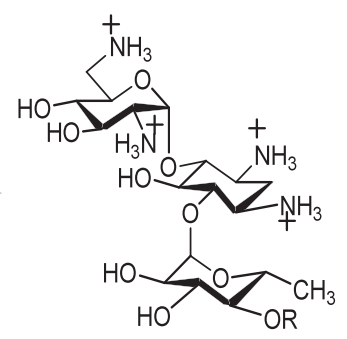

FG01 R $=\mathrm{C}_{4} \mathrm{H}_{9} \quad 45 \%$ FG08 $\mathrm{R}=\mathrm{C}_{8} \mathrm{H}_{17} \quad 32 \%$ FG02 R $=\mathrm{C}_{12} \mathrm{H}_{25} \quad 35 \%$

Figure 1 Scheme for synthesis of FG08, FGO1 and FG02. Neamine derivative compound $\mathbf{3}$ is described by Li et al. ${ }^{22}$ 


\section{Leaf infection assay}

Suspensions of $F$. graminearum macroconidia $\left(2.0 \times 10^{4} \mathrm{ml}^{-1}\right)$ were prepared in sterile solution of $0.25 \%\left(\mathrm{wt} \mathrm{vol}^{-1}\right)$ agar and $0.2 \%$ (by volume) of Tween 20 and mixed with equal volumes of FG08 or kanamycin B made in the same solution. Leaf infection assay methods were previously described. ${ }^{28}$

\section{FHB disease suppression}

Rapid-maturing cultivar Apogee ${ }^{29,30}$ was grown for 5-6 weeks in a greenhouse to the flowering stage. Florets (one per spikelet) were treated with a solution of FG08 $\left(10 \mu \mathrm{l}, 5\right.$ and $1080 \mu \mathrm{g} \mathrm{ml}^{-1}$, and then inoculated with suspension of F. graminearum macroconidia $\left(10 \mu \mathrm{l}, 10^{5}\right.$ conidia $\left.\mathrm{ml}^{-1}\right)$. After 4 days, the spikelets were visually inspected for disease symptoms (chlorosis, spikelet curling and dehydration).

\section{Mechanism of action}

Fungal membrane permeability was assessed using SYTOX green. ${ }^{31}$ Haemolytic activity was determined using sheep erythrocytes according to previously described methods. ${ }^{32}$

Detailed procedural descriptions accompany this paper (Supplementary Information).

\section{RESULTS AND DISCUSSION}

An analog of kanamycin B, FG08, was synthesized with phenyl 2,3di-o-benzyl-6-deoxy-4-o-n-octyl-1-thio- $\beta$-D-glucopyranoside as the $\alpha$-glycosyl donor (Figure 2). Related analogs were synthesized with kanosamine modifications that included placement of an axial or equatorial hydroxyl group at the $4^{\prime \prime}$ position and deoxygenation at the $6^{\prime \prime}$ position (Supplementary Figures $1 \mathrm{~B}$ and D and 3). Also, analogs were synthesized that were deaminated at the $3^{\prime \prime}$ position (Supplementary Figures $1 \mathrm{~B}$ and $\mathrm{D}$ and 3 ), deoxygenated at the $6^{\prime \prime}$ position or with replacement of the kanosamine $6^{\prime \prime}-\mathrm{CH}_{2} \mathrm{OH}$ with a hydrogen atom (Supplementary Figures $1 \mathrm{~B}-\mathrm{F}$ and 4 ), and with attachment of hydroxyaminoalkyl chains in place of the C8 alkyl chain at the $4^{\prime \prime}$ position (Supplementary Figures $1 \mathrm{C}$ and E).

FG08 showed little or no growth inhibition of Gram-positive and Gram-negative bacteria (Figure 3, Table 1) with MICs that were at least 125 -fold higher than shown by kanamycin B (Table 1). Instead, FG08 was fungicidal to a variety of yeasts, oomycetes and true fungi with MICs ranging between 3.9 and $31.3 \mu \mathrm{g} \mathrm{ml}^{-1}$ (Table 1, Figure 3). Like kanamycin B, all synthesized analogs of FG08 lacked antifungal activity (Supplementary Table 1). Therefore, the antibacterial to

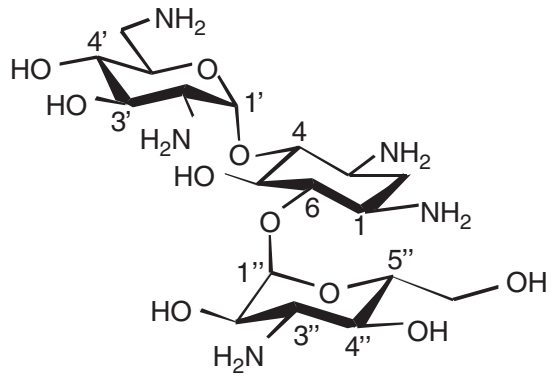

kanamycin B

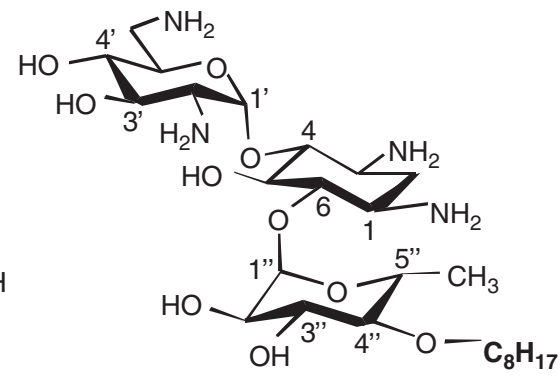

FG08

Figure 2 Structures of kanamycin B and FG08. FG08 differs from kanamycin B with C8 alkyl, hydroxyl and H vs H, amino and OH groups at the 4", 3" and $5^{\prime \prime}$ positions, respectively.

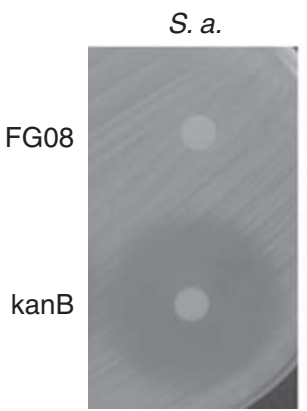

E. C.

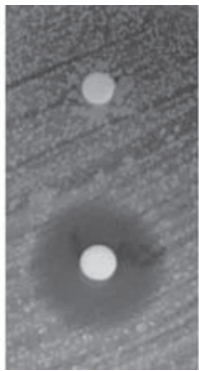

S. C.

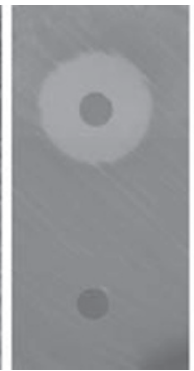

C. c.

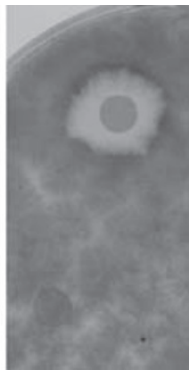

FG08 concentration $\times 1 \mathrm{mg} \mathrm{mL}^{-1}$

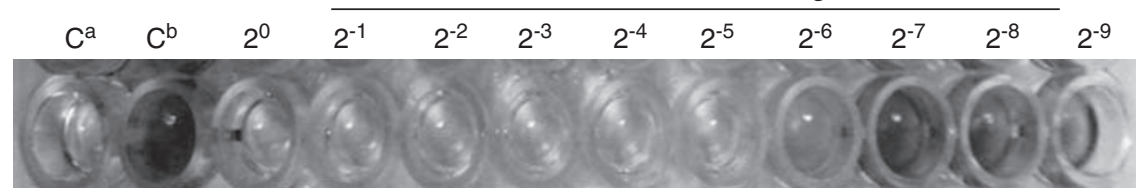

Figure 3 Antimicrobial activities of FG08 and kanamycin B. (Upper panel) Disk agar diffusion assays show that FG08 is antifungal, but not antibacterial in contrast to kanamycin B (kanB). Water solutions of FG08, kanamycin B, at concentrations of $10.9,10.0 \mathrm{mg} \mathrm{ml}^{-1}$, respectively (each of volume $8 \mu \mathrm{l}$ ), were applied to paper disks. (Lower panel) $\mathrm{FG08}$ has an antifungal MIC of $31.3 \mu \mathrm{g} \mathrm{ml} \mathrm{I}^{-1}$ against $F$. graminearum as revealed by microbroth dilution inhibition assays (also see Table 1). Controls are $\mathbf{C}^{\mathbf{a}}$ (medium only) and $\mathbf{C}^{\mathbf{b}}$ (no compound). S.a., Staphylococcus aureus; E.c., Escherichia coli; S. c., Saccharomyces cereviseae; C.c., Cladosporium cladosporioides. 
Table 1 Minimal inhibitory concentrations (MICs) of FG08 and kanamycin B against bacteria and fungi

\begin{tabular}{|c|c|c|}
\hline \multirow[b]{2}{*}{ Organism } & \multicolumn{2}{|c|}{$M I C\left(\mu g m I^{-1}\right)^{a}$} \\
\hline & FG08 & Kanamycin B \\
\hline \multicolumn{3}{|l|}{ Bacteria } \\
\hline Escherichia coli TG1 & $125-250$ & 1.95 \\
\hline Staphylococcus aureus ATC 25923 & 250 & $<0.98$ \\
\hline Pseudomonas aeruginosa (ATCC 27853) & 250 & 1.95 \\
\hline Enterococcus faecalis (ATCC 29212) & $125-250$ & $<0.98$ \\
\hline Klebsiella pneumoniae (ATCC 138883) & 250 & 1.95 \\
\hline Klebsiella pneumomiae (ATCC 700603) & 250 & 1.95 \\
\hline \multicolumn{3}{|l|}{ Fungi } \\
\hline Rhodotorula pilimanae (ATCC26423) & 7.8 & $>250$ \\
\hline Candida albicans (ATCC10231) & 31.3 & $>250$ \\
\hline Saccharomyces cerevisiae W303 & 3.9 & $>250$ \\
\hline Fusarium graminearum B-4-5A & 31.3 & $>250$ \\
\hline Fusarium oxysporum & 7.8 & $>250$ \\
\hline Ulocladium spp. & 7.8 & $N D^{b}$ \\
\hline Pythium irregulare & 15.6 & ND \\
\hline Pythium ultimum & 15.6 & ND \\
\hline Phytophthora parasitica & 15.6 & ND \\
\hline Rhizopus stolonifer & 31.3 & ND \\
\hline Cladosporium cladosporioides & 31.3 & ND \\
\hline Curvularia brachyspora & 31.3 & ND \\
\hline Bortrytis cinerea & 31.3 & ND \\
\hline Phoma spp. & 31.3 & ND \\
\hline
\end{tabular}

aMicrobroth dilution assays were performed at least twice, and each in triplicate.

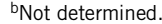

antifungal activity 'switch' in the FG08 analog appears to be mainly due to the occurrence of a C8 alkyl chain at the $4^{\prime \prime}$ position. Finally, structure-bioactivity analyses were conducted as a function of the length of the $4^{\prime \prime}$ alkyl chain. Analogs with shorter (C4) or longer (C12) alkyl chains had lower antifungal activities than FG08 (Supplementary Figure 2). Therefore, the C8 alkyl chain imparts optimal antifungal activity.

The fungus F. graminearum - the causative agent of FHB-was susceptible to FG08 as observed with in vitro susceptibility tests (Figure 3, lower panel). FG08 was investigated for its ability to control FHB of wheat. First, leaf infection assays with seedlings (2 leaves, 14 days post germination) that correlate with $\mathrm{FHB}$ disease potential ${ }^{28}$ were used to assess FG08's ability to suppress in planta F. graminearum infection. Suspensions of F. graminearum (strain B-4-5A) macroconidia were premixed with FG08 or kanamycin B each at 30 and $180 \mu \mathrm{g} \mathrm{ml}^{-1}$ concentrations, $0.25 \%$ agar and Tween $20(0.2 \%$, by volume) and $10 \mu \mathrm{l}$ of the mixture applied on the surface at the middle of primary leaves of FHB susceptible (Alsen) and resistant (Frontana) cultivar seedlings at the two-leaf growth stage. With the Alsen cultivar, leaves inoculated with mixtures containing FG08 at $30 \mu \mathrm{g} \mathrm{ml}^{-1}$ showed 5- and 1.25-fold less leaf lesion area and degree of chlorosis, respectively, when compared with non-FG08 treated controls (Figure 4). At $180 \mu \mathrm{g} \mathrm{ml}^{-1}$, macroconidia-induced lesion formation was not measurable because of possible phytotoxicity at this concentration as suggested by controls with no macroconidia inoculation (Figure 4, lower panel). In contrast, kanamycin B did not suppress lesion formation at $180 \mu \mathrm{g} \mathrm{ml}^{-1}$. As expected, leaves of resistant cultivar Frontana showed relatively low levels of lesion formation and chlorosis with or without macroconidia inoculation, and these parameters were
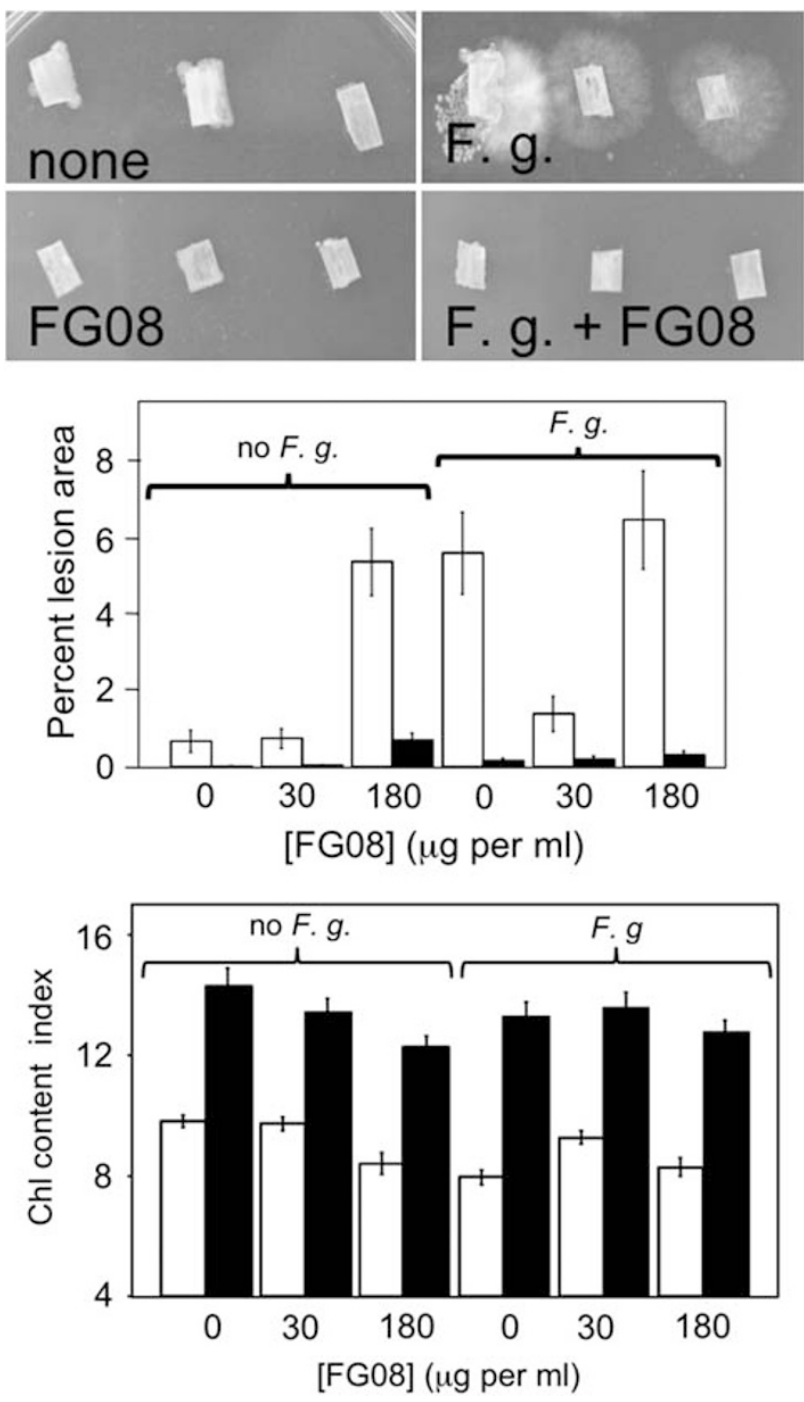

Figure 4 FG08 suppression of wheat leaf infection after exposure to F. graminearum ( $F$. g.). Two-leaf stage FHB-susceptible Alsen (blank bars) or FHB-resistant Frontana (black bars) wheat leaves were inoculated with F. graminearum macroconidia and treated with FG08 $(10 \mu \mathrm{l}$ drop at the inoculation site) $24 \mathrm{~h}$ later. (Upper panel) Cut segments from leaves treated with $30 \mu \mathrm{gml}^{-1}$ FG08 did not show subsequent mycelial growth when incubated on potato dextrose agar medium, and (middle panel) this level of FG08 caused a 5 -fold decrease in leaf lesions caused by $F$. graminearum infection. (Middle panel) FG08 at $30 \mu \mathrm{g} \mathrm{ml}^{-1}$ was not phytotoxic as seen by no increase in lesion area with both FHB susceptible (Alsen) and resistant (Frontana) cultivars and (lower panel) no decrease in chlorophyll (Chl) content. FG08 at $180 \mu \mathrm{g} \mathrm{ml}^{-1}$ showed phytotoxicity in this assay.

not influenced by exposure to FG08 (Figure 4, upper and middle panels). Subsequent incubation of macroconidia-inoculated and FG08 $\left(30 \mu \mathrm{g} \mathrm{ml}^{-1}\right)$-treated leaf segments on potato dextrose agar medium $\left(25^{\circ} \mathrm{C}, 5\right.$ days) showed no mycelia growth indicating that FG08 at this concentration was fungicidal (Figure 4, upper panel). Altogether, these results show that FG08 at concentrations equal to their in vitro MICs afforded in planta protection against F. graminearum infection when applied to leaves of susceptible wheat seedlings.

Second, the ability of FG08 to suppress FHB symptoms of wheat head spikelets exposed to F. graminearum macroconidia was examined. Cultivar Apogee-a rapidly maturing and FHB-susceptible 

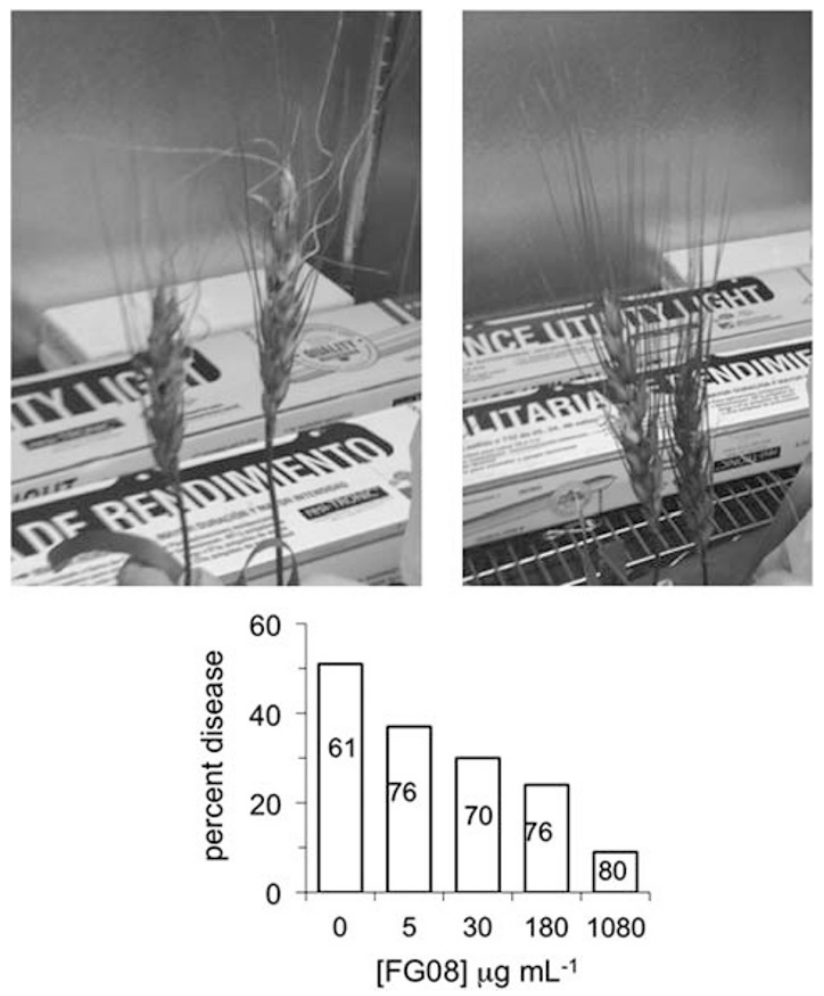

Figure 5 FG08 suppression of FHB disease in wheat spikelet florets. Florets (one per spikelet) of early flowering heads (cultivar Apogee) were pre-treated with FG08 $\left(10 \mu \mathrm{l}, \quad 5-1080 \mu \mathrm{g} \mathrm{ml}^{-1}\right.$ followed by inoculation with F. graminearum (F.g.) macroconidia $\left(10 \mu \mathrm{l}, 10^{5}\right.$ conidia $\left.\mathrm{ml}^{-1}\right) 24 \mathrm{~h}$ later. (Upper panel) Without FG08 pretreatment, FHB symptoms (chlorosis and curled spikes) were evident within 4 days, but suppressed with pretreatment. (Lower panel) Suppression was observed at FG08 concentrations between 5 and $1080 \mathrm{\mu g} \mathrm{ml}^{-1}$ with reduced disease incidences between 27 and $82 \%$, respectively. Uninoculated spikelets had visually healthy florets following FG08 treatments at concentrations ranging between 5 and $1080 \mu \mathrm{g} \mathrm{ml}^{-1}$. Numbers in the bars indicate the numbers of florets examined ( $8-12$ florets per spikelet), and the florets were scored as diseased or not diseased on the basis of visual inspection.

variety of wheat-was used. ${ }^{29,30}$ FG08 pre-treatment of Apogee spikelet florets at concentrations as low as 5 and $30 \mu \mathrm{g} \mathrm{ml}^{-1}$ reduced the rate of spikelet infection by 29 and $49 \%$, respectively, over controls that were not pretreated with FG08 (Figure 5). FG08 pretreatments at $1080 \mu \mathrm{g} \mathrm{ml}^{-1}$ reduced disease incidence by $82 \%$. FG08 alone did not show toxicity in spikelets as observed in controls that were not inoculated with macroconidia, even at the highest concentration tested $\left(1080 \mu \mathrm{g} \mathrm{ml}^{-1}\right)$. These results show that FG08 pretreatment of wheat spikelets protects against F. graminearum infection with no phytotoxicity. As, this procedure mimics the spread of FHB in the field, these findings are particularly relevant to FG08's potential for controlling this disease.

The C8 alkyl chain should confer amphipathic properties to FG08. This raises the prospect that its antifungal activity is because of perturbation of membrane function. Studies with fluorescent dye SYTOX green (Molecular Probes, Invitrogen, Carlsbad, CA USA) were conducted to determine if FG08 increases cell surface membrane permeability of fungi. At levels close to the fungal MICs, FG08 allowed dye permeation of $C$. albicans cells and F. graminearum hyphae (Figure 6a). With C. albicans, FG08 was about 12 times more effective than kanamycin B (Figure 6b). The results suggest that FG08's mode
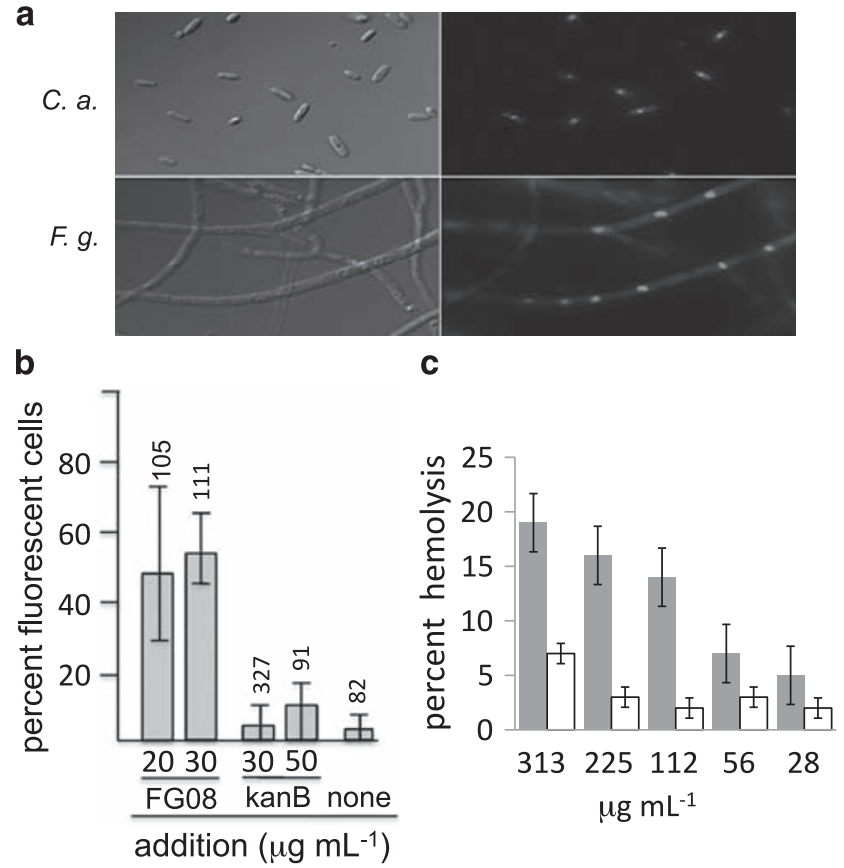

Figure 6 FG08 effects on membrane permeability. (a) Addition of FG08 at 30 and $10 \mu \mathrm{g} \mathrm{ml}^{-1}$ (10 min) increased the permeability of $C$. albicans (C. a.) cells and $F$. graminearum ( $F$. g.) hyphae, respectively, to SYTOX green $(0.2 \mu \mathrm{M})$. (b) FG08 is more effective than kanamycin B (kanB) (both with 10 min exposure) in causing SYTOX green dye permeation in C. albicans cells. At $30 \mu \mathrm{g} \mathrm{ml}^{-1}$, FG08 was $\sim 12$ times more effective than kanamycin B. Triton X100 ( $1 \%$ ) gave $100 \%$ dye permeation (data not shown). Numbers above the range bars indicate number of cells analyzed. (c) Neither FG08 (gray bars) or kanamycin B (blank bars) caused hemolysis of sheep erythrocytes at concentrations equal to their antifungal or antibacterial MICs, respectively.

of action differs from that of kanamycin B and appears to involve the perturbation of fungal membranes. Whether FG08's membrane effects are direct (for example, pore formation) or indirect or both are not known. The rapidity of FG08's influence on dye permeability (10 min), however, suggests a role for direct membrane effects. In contrast, FG08 did not lyse more than $20 \%$ of erythrocytes at $313 \mu \mathrm{g} \mathrm{ml}^{-1}$ (10-fold higher than the antifungal MIC) and only $2 \%$ at $28 \mu \mathrm{g} \mathrm{ml}^{-1}$ (Figure 6c). Therefore, at antifungal MICs, FG08 does not seem to act as a surface-active agent that non-specifically disrupts membranes.

In summary, a novel neamine aminoglycoside analog, FG08-with a linear C8 alkyl chain as a major structural feature-is antifungal in contrast to its prototype analog kanamycin B that is predominantly antibacterial. FG08 also lacks antibacterial activity and appears to have effects on fungal membrane permeability. These findings suggest that FG08 and its next generation analogs may have agrofungicidal and possibly therapeutic applications. With a different mechanism of action, it may be speculated that FG08 would not be subject to the resistance mechanisms that have evolved for the classical aminoglycosides. The overall finding of this study, whereby a chemically simple modification of an obsolete drug (for example, kanamycin B) yields a potentially useful one, suggests a novel drug development strategy.

\section{ACKNOWLEDGEMENTS}

We acknowledge L Takemoto and H HLiu for technical assistance, B Kropp and A DeLucca for fungal strains, and B Bugbee for Apogee wheat seeds. The research was funded by Baicor LC, the National Institutes of Health (Grant no. AI053138 to CW T Chang), the Utah Science Technology and Research 
initiative, and the Utah Agricultural Experiment Station (project UTA00569 to JYT). (This publication is approved as UAES publication no. 8208.)

1 Lee, H. B. et al. Activity of some aminoglycoside antibiotics against true fungi, Phytophthora and Pythium species. J. Appl. Microbiol. 99, 836-843 (2005).

2 Lynch, S. R. \& Puglisi, J. D. Structural origins of aminoglycoside specificity for prokaryotic ribosomes. J. Mol. Biol. 306, 1037-1058 (2001).

3 Wilhelm, J. M., Pettitt, S. E. \& Jessop, J. J. Aminoglycoside antibiotics and eukaryotic protein synthesis: structure-function relationships in the stimulation of misreading with a wheat embryo system. Biochem. 17, 1143-1149 (1978).

4 Allen, H. K. et al. Call of the wild: antibiotic resistance genes in natural environments. Nat. Rev. Microbiol. 8, 251-259 (2010).

5 McManus, P. S., Stockwell, V. O., Sundin, G. W. \& Jones, A. L. Antbiotic use in plant agriculture. Ann. Rev. Phytopathol. 40, 443-465 (2003).

6 Vakulenko, S. B. \& Mobashery, S. Versatility of aminoglycosides and prospects for their future. Clin. Microbiol. Rev. 16, 430-450 (2003).

7 McGaha, S. M. \& Champney, W. S. Hygromycin B inhibition of protein synthesis and ribosome biogenesis in Escherichia coli. Antimicrob. Agents Chemother. 51, 591-596 (2007).

8 Perzynski, S., Cannon, M., Cundliffe, E., Chahwala, S. B. \& Davies, J. Effects of apramycin, a novel aminoglycoside antibiotic on bacterial protein synthesis. Eur. J. Biochem. 99, 623-628 (1979).

9 Hermann, T., Tereshko, V., Skripkin, E. \& Patel, D. J. Apramycin recognition by the human ribosomal decoding site. Blood Cells, Mol., Dis. 38, 193-198 (2007).

10 Knight, S. C. et al. Rationale and perspectives on the development of fungicides. Ann. Rev. Phytopathol. 35, 349-372 (1997).

11 Verweij, P. E., Snelders, E., Kema, G. H., Mellado, E. \& Melchers, W. J. Azole resistance in Aspergillus fumigatus: a side-effect of environmental fungicide use? Lancet Infect. Dis. 9, 789-795 (2009).

12 Goswami, R. S. \& Kistler, H. C. Heading for disaster: Fusarium graminearum on cereal crops. Mol. Plant Pathol. 5, 515-525 (2004)

13 Umezawa, H. et al. Production and isolation of a new antibiotic: kanamycin. J. Antibiot. (Tokyo) 10, 181-188 (1957).

14 Begg, E. J. \& Barclay, M. L. Aminoglycosides 50 years on. Brit. J. Clin. Pharmacol. 39, 597-603 (1995).

15 Matsuno, T., Yoneta, T., Fukatsu, S. \& Umemura, E. An improved synthesis of 3',4'dideoxykanamycin B. Carbohydr. Res. 109, 271-275 (1982).

16 Kondo, S., linuma, K., Yamamoto, H., Ikeda, Y. \& Maeda, K. Letter: Synthesis of (S)-4amino-2-hydroxybutyryl derivatives of $3^{\prime}, 4^{\prime}$-dideoxykanamycin B and their antibacterial activities. J. Antibiot. (Tokyo) 26, 705-707 (1973).

17 Kondo, S., linuma, K., Yamamoto, H., Maeda, K. \& Umezawa, H. Letter: Syntheses of 1-N-(S)-4-amino-2-hydroxybutyryl)-kanamycin B and -3', 4'-dideoxykanamycin B active against kanamycin-resistant bacteria. J. Antibiot. 26, 412-415 (1973).
18 Kawaguchi, H., Naito, T., Nakagawa, S. \& Fujisawa, K. I. BB-K 8, a new semisynthetic aminoglycoside antibiotic. J. Antibiot. (Tokyo) 25, 695-708 (1972).

19 Mingeot-Leclercq, M. P. et al. New derivatives of kanamycin-B obtained by modifications and substitutions in position $6^{\prime \prime} .2$. Invitro and computer-aided toxicological evaluation with respect to interactions with phosphatidylinositol. J. Med. Chem. 34, 1476-1482 (1991).

20 Van Schepdael, A. et al. New Derivatives of Kanamycin-B Obtained by Modifications and Substitutions in Position 6" .1. Synthesis and Microbiological Evaluation. J. Med. Chem. 34, 1468-1475 (1991).

$21 \mathrm{Li}$, J. et al. Application of glycodiversification: expedient synthesis and antibacterial evaluation of a library of kanamycin B analogues. Org. Lett. 6, 1381-1384 (2004).

22 Li, J., Chen, H.- N., Chang, H., Wang, J. \& Chang, C.- W. T. Tuning the regioselectivity of the staudinger reaction for the facile synthesis of kanamycin and neomycin class antibiotics with N-1 modification. Org. Lett. 7, 3061-3064 (2005).

23 Wang, J. et al. Glycodiversification for the optimization of the kanamycin class aminoglycosides. J. Med. Chem. 48, 6271-6285 (2005).

24 Zhang, L. \& Takemoto, J. Y. Mechanism of action of Pseudomonas syringae phytotoxin, syringomycin. Interaction with the plasma membrane of wild-type and respiratorydeficient strains of Saccharomyces cerevisiae. Biochim. Biophys. Acta 861, 201-204 (1986).

25 Sambrook, J., Fritsch, E. F. \& Maniatis, T. Molecular Cloning: A Laboratory Manual (Cold Spring Harbor Laboratory, Cold Spring Harbor, New York, 1989).

26 NCCLS. Methods for Dilution Antimicrobial Susceptibility Tests for Bacteria that Grow Aerobically Approved Standard M7-A3, (National Committee for Clinical Laboratory Standards, Wayne, Pa, 1993).

27 NCCLS. Reference Method for Broth Dilution Antifungal Susceptibility Testing of Filamentous Fungi Approved standard M38-A., (National Committee for Clinical Laboratory Standards, Wayne, PA, 2002).

28 Evans, C. K. \& Dill-Macky, R. in Reaction of primary leaves of 26 wheat genotypes inoculated with macroconidia of Fusarium graminearum at the seedling stage and assessed for lesion length and deoxynivalenol accumulation at $96 \mathrm{~h}$ post-Inoculation in 2003. National Fusarium Head Blight Forum (eds Canty, S.M., Lewis, J. \& Ward, W.) 138 (East Lansing: Michigan State University, Bloomington, MN, 2003).

29 Bugbee, B., Koerner, G., Albrechtsen, R., Dewey, W. \& Clawson, S. Registration of 'USU-Apogee' wheat. Crop Sci. 37, 626 (1997).

30 Mackintosh, C., Garvin, D., Radmer, L., Heinen, S. \& Muehlbauer, G. A model wheat cultivar for transformation to improve resistance to Fusarium Head Blight. Plant Cell Rep. 25, 313-319 (2006).

31 van der Weerden, N. L., Lay, F. T. \& Anderson, M. A. The plant defensin, NaD1, enters the cytoplasm of Fusarium oxysporum hyphae. J. Biol. Chem. 283, 14445-14452 (2008).

32 Sorensen, K. N., Kim, K. H. \& Takemoto, J. Y. In vitro antifungal and fungicidal activities and erythrocyte toxicities of cyclic lipodepsinonapeptides produced by Pseudomonas syringae pv. syringae. Antimicrob. Agents Chemother. 40, 2710-2713 (1996).

Supplementary Information accompanies the paper on The Journal of Antibiotics website (http://www.nature.com/ja) 